\title{
Optimal intermittent administration interval of parathyroid hormone 1-34 for bone morphogenetic protein-induced bone formation in a rat spinal fusion model
}

\author{
Tetsutaro Abe $^{1}$ | Masashi Miyazaki ${ }^{1} \odot$ | Toshinobu Ishihara $^{1}$ | Shozo Kanezaki ${ }^{1}$ | \\ Yuhta Tsubouchi $^{2}$ | Hiroshi Tsumura ${ }^{1}$
}

${ }^{1}$ Faculty of Medicine, Department of Orthopedic Surgery, Oita University, Oita, Japan

${ }^{2}$ Department of Rehabilitation, Oita University, Oita, Japan

\section{Correspondence}

Masashi Miyazaki, Faculty of Medicine, Department of Orthopedic Surgery, Oita University, 1-1 Idaigaoka, Hasama-machi, Yufu-shi, Oita 879-5593, Japan.

Email: masashim@oita-u.ac.jp

Funding information JSPS KAKENHI, Grant/Award Number: JP $19 K 09556$

\begin{abstract}
Introduction: Both bone morphogenetic protein 2 (BMP-2) and teriparatide (parathyroid hormone [PTH] 1-34) are used to enhance bone healing. There is still no established opinion regarding the optimum dose and administration method. We investigated the optimal administration method for the combination of BMP-2 and PTH 1-34 in a rat spinal fusion model.

Methods: Group I was implanted with a control carrier. Groups II, III, and IV were implanted with a carrier containing $3 \mu \mathrm{g}$ of recombinant human BMP-2 (rhBMP-2). In addition, following implantation, PTH 1-34 injections were administered to Group III thrice a week (total, $180 \mu \mathrm{g} / \mathrm{kg} /$ week) and Group IV six times a week (total, $180 \mu \mathrm{g}$ / $\mathrm{kg} /$ week). The rats were euthanized after 8 weeks, and their spines were explanted; assessed by manual palpation, radiographs, and high-resolution micro-computed tomography (micro-CT); and subjected to histological analysis. Serum markers of bone metabolism were also analyzed.

Results: Manual palpation tests showed that the fusion rates in Groups III and IV were considerably higher than those in Group I. They also had higher radiographic scores than Group I and II. Micro-CT analysis revealed Tb.Th in the Group IV had higher values than that in the Group I, II, III with significant differences and Tb.Sp in the Group IV had lower values than that in the Group I, II, III with significant differences. Serum marker analysis revealed that Group IV had higher osteocalcin and lower tartrate-resistant acid phosphatase-5b than Group III. Histological analysis indicated that Group IV had enhanced trabecular bone structure.

Conclusions: Frequent administration of PTH may be better in making thicker and strengthening the trabecular bone structure in newly formed bone in the rat spinal fusion model using insufficient BMP-2.

KEYWORDS

bone fusion, bone morphogenetic protein, parathyroid hormone, rat spinal fusion model
\end{abstract}




\section{1 | INTRODUCTION}

There are a few past reports of bone fusion caused by the combination of spinal arthrodesis and various drugs. Spinal arthrodesis is a fundamental treatment option for spinal pathologies and is one of the most common spinal procedures, with more than 200000 surgeries performed in the United States each year. ${ }^{1}$ In this procedure, bone grafts are used to restore mechanical stability to the affected spinal segment by providing bridging bone between vertebrae. Because successful bone fusion between unstable spinal segments leads to pain relief and neurologic recovery, the efficacy of this procedure has gained wide acceptance, and the number of these types of surgery has increased annually with an increase in the aged population. ${ }^{2-5}$

Bone morphologic proteins (BMPs) are members of the transforming growth factor- $\beta$ superfamily ${ }^{6}$ and are powerful osteoinductive molecules. BMPs are also considered to promote new osteoclast formation because they stimulate the production of receptor activator of nuclear factor kappa- $\beta$ ligand osteoblasts and help ensure mature osteoclast survival; therefore, BMPs participate in bone matrix resorption. $^{7-8}$ The osteoinductive effects of recombinant human BMP-2 (rhBMP-2) for spinal fusion have been shown in animal models and clinical trials. ${ }^{9-13}$ Although BMPs are approved for clinical use, clinical trial results have shown that high doses are required to induce adequate bone fusion because of the following reasons: (1) solubility of the molecules, (2) easy diffusion of the molecules away from the fusion site, and (3) in vivo inactivation. ${ }^{14}$ In addition, BMPs are expensive; therefore, their usefulness may be limited by their expense. As a result, a number of strategies are being developed to provide a safer, less expensive, and more efficacious spinal fusion using rhBMP-2.

Teriparatide (parathyroid hormone [PTH] 1-34) is an anabolic drug, and its efficacy as an osteoporosis drug has been widely verified through experimental and clinical studies. ${ }^{15-18}$ Although PTH can have bone resorption effects with continuous administration; it can also accelerate bone formation with intermittent administration. PTH 1-34 could also enhance fracture healing not only in ovariectomized rats, but also in intact rats. ${ }^{19,20}$ The clinical use of PTH 1-34 to accelerate fracture healing has been attempted, and the combination of PTH 1-34 and BMPs has been shown to favor spinal fusion. ${ }^{21}$ However, the optimal intermittent administration interval of PTH1-34 has not been revealed.

We previously reported that the synergistic effect of rhBMP-2 and PTH 1-34 administered systemically as a single dose at the optimal time was efficacious for fracture repair and significantly enhanced bone fusion in a rat femoral fracture model. ${ }^{22}$ The purpose of this study was to clarify the optimal dosing interval and administration method for the combination of rhBMP-2 and PTH 1-34 in a rat spinal fusion model.

\section{2 | MATERIALS AND METHODS}

\section{1 | Preparation of matrices}

CollaCote (Zimmer/dental) is a biodegradable collagen scaffolding used for cellular attachment. Although a collagen sponge has been used clinically as a carrier for rhBMP-2, ${ }^{23,24}$ CollaCote has an allograft matrix possessing hemostatic function that facilitates early clot formation and wound stabilization. The final concentration of rhBMP-2 (Peprotech, Rocky Hill, New Jersey) was dissolved in phosphate buffered saline $(\mathrm{pH} \mathrm{7.5)}$ and applied to CollaCote. CollaCote was cut with a scalpel into $5 \mathrm{~mm} \times 20 \mathrm{~mm}$ strips and placed with rhBMP-2 in an Eppendorf tube that was left overnight at $4{ }^{\circ} \mathrm{C}$ prior to implantation. Similarly, $100 \mu \mathrm{l}$ of rhBMP-2-free phosphate buffered saline was added to CollaCote to obtain rhBMP-2-free CollaCote.

\section{2 | Animals}

All animal studies were approved by the Oita University Animal Research Committee, and experiments conformed to all guidelines and regulations for the protection of animal welfare (protocol No. 1624002).

\section{3 | Study groups}

A total of 52 male Sprague-Dawley rats (8-10 weeks old; CLEA Japan, Inc., Tokyo, Japan) were divided into four groups. Group I $(n=10)$ included animals that were implanted with a control carrier alone. Group II $(n=14)$ included animals that were implanted with carriers containing $3 \mu \mathrm{g}$ of rhBMP-2. Group III $(n=14)$ included animals that were implanted with carriers containing $3 \mu \mathrm{g}$ of rhBMP-2, followed by injections of PTH 1-34 (Teribone; Asahi Kasei Pharma, Tokyo, Japan) $(60 \mu \mathrm{g} / \mathrm{kg})$ three times a week (total, $180 \mu \mathrm{g} / \mathrm{kg} /$ week). Group IV ( $n=14$ ) included animals that were implanted with a carrier containing $3 \mu \mathrm{g}$ of rhBMP-2, followed by injections of PTH 1-34 (30 $\mu \mathrm{g} / \mathrm{kg})$ six times a week (total, $180 \mu \mathrm{g} / \mathrm{kg} /$ week). Rats in groups III and IV were subcutaneously injected with PTH beginning 1 week after surgery. The injections were continued until immediately before the rats were euthanized at 8 weeks postperatively.

\subsection{Surgical technique for constructing the L4-L5 posterolateral spinal fusion model}

A posterior midline incision was made on the skin. Next, two separate paramedian incisions were made $3 \mathrm{~mm}$ from the midline in the lumbar fascia, and the transverse processes were exposed. The transverse processes of L4 and L5 were decorticated using a lowspeed burr. Subsequently, CollaCote with or without rhBMP-2 was implanted on each side. The fascial and skin incisions were closed with a 3-0 absorbable suture. Immediately following surgery and on subsequent days, the rodents received analgesics (buprenorphine subcutaneously and paracetamol). The rodents were housed in separate cages and fed food and water ad libitum, and their condition was monitored on a daily basis. The rats were humanely euthanized 8 weeks postoperatively. 
TAB LE 1 Assessment of spinal fusion via manual palpation

\begin{tabular}{|c|c|c|c|c|}
\hline Treatment group & & $\begin{array}{l}\text { No. assessed } \\
\text { manually for fusion }\end{array}$ & $\begin{array}{l}\text { No. assessed } \\
\text { as fused }\end{array}$ & Fusion rate (\%) \\
\hline Group I & Carrier alone & 20 & 0 & 0 \\
\hline Group III & $3 \mu \mathrm{g}$ rhBMP-2 + PTH (3 times/week, total $180 \mu \mathrm{g} / \mathrm{kg}$ ) & 28 & 8 & $28.6^{*}$ (vs Group I) \\
\hline Group IV & $3 \mu \mathrm{g}$ rhBMP-2 + PTH (6 times/week, total $180 \mu \mathrm{g} / \mathrm{kg}$ ) & 28 & 10 & $35.7^{*}$ (vs Group I) \\
\hline
\end{tabular}

Note: The Group III and IV had higher fusion rates than the Group I with significant differences. No significant difference was found between the other groups.

${ }^{*} p<0.05$.

TABLE 2 Radiographic scores at 8 weeks

\begin{tabular}{llll} 
Treatment group & & No. studied radiographically & Score at 8 weeks (mean \pm SD) \\
\hline Group I & Carrier alone & 20 & $0.11 \pm 1.41$ \\
Group II & $3 \mu$ g rhBMP-2 & 28 & $0.48 \pm 1.55$ \\
\hline Group III & $3 \mu$ g rhBMP-2 + PTH (3 times/week, total $180 \mu \mathrm{g} / \mathrm{kg})$ & 28 & $1.75 \pm 1.37^{*}$ (vs Group I and II) \\
Group IV & $3 \mu \mathrm{g} \mathrm{rhBMP-2}+$ PTH (6 times/week, total $180 \mu \mathrm{g} / \mathrm{kg})$ & 28 & $2.11 \pm 1.21^{*}$ (vs Group I and II) \\
\hline
\end{tabular}

${ }^{*} p<.05$. The Group III and IV had higher radiographic scores than the Group I and II with significant differences.

No significant difference was found between the other groups.
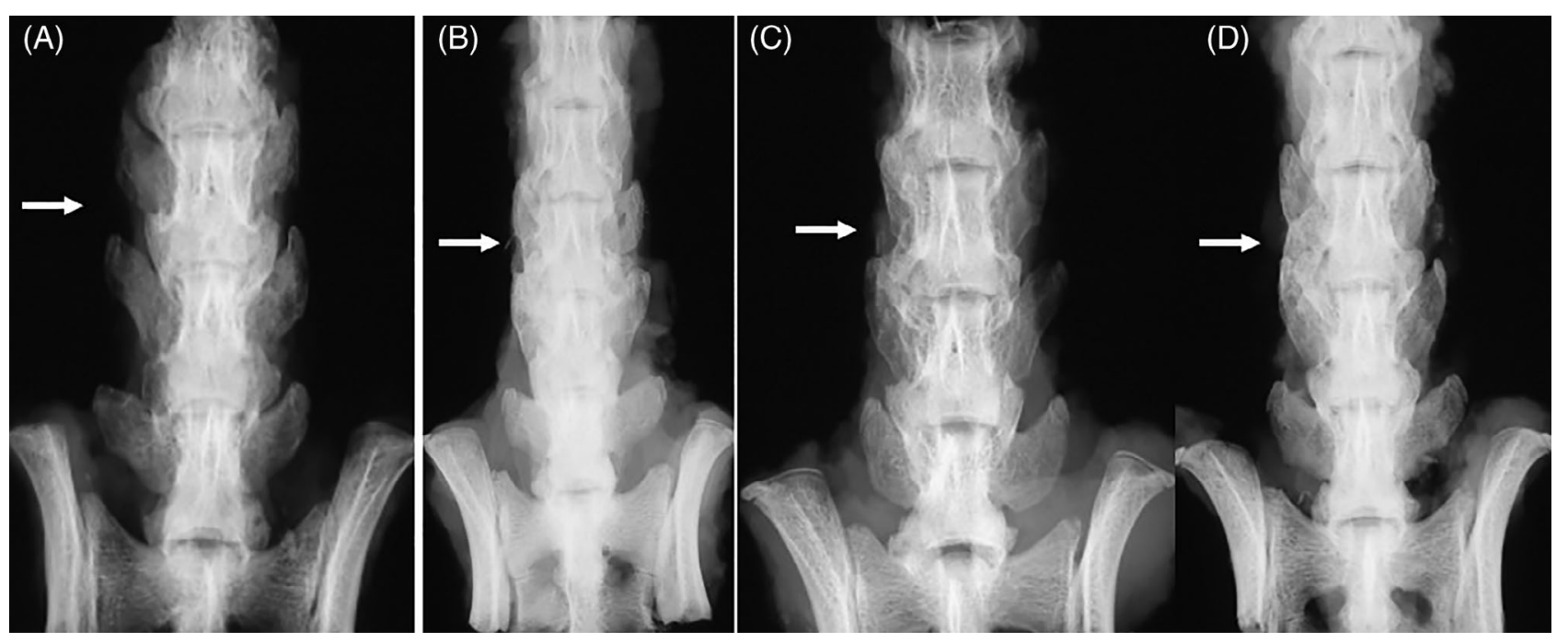

FIGURE 1 Radiographs of rat spines obtained at 8 weeks post posterolateral lumbar fusion surgery. (A) Group I (carrier alone), (B) Group II (carrier containing $3 \mu \mathrm{g} \mathrm{rhBMP-2),} \mathrm{(C)} \mathrm{Group} \mathrm{III} \mathrm{(carrier} \mathrm{containing} 3 \mu \mathrm{g} \mathrm{rhBMP-2}+\mathrm{PTH}$ (three times [60 $\mu \mathrm{g} / \mathrm{kg}] / \mathrm{week}$, total $180 \mu \mathrm{g} / \mathrm{kg}$ )), and (D) Group IV (carrier containing $3 \mu \mathrm{g}$ rhBMP-2 + PTH (six times[30 $\mu \mathrm{g} / \mathrm{kg}] /$ week, total $180 \mu \mathrm{g} / \mathrm{kg}$ ))

\section{5 | Manual assessment of fusion}

Eight weeks postimplantation, the explanted spines were manually tested for intersegmental motion by three blinded independent observers. ${ }^{25-31}$ The explanted lumbar spine was palpated gently, and the lateral side bending motion at the L4-L5 level was compared with the motion at the adjacent levels above (L3-L4) and below (L5-L6). The absence of motion was considered a successful fusion. Any motion detected between the transverse processes was considered a failure of fusion. The spine was designated as "not fused" if any of the three observers graded the spine as not fused. The spines were scored as either fused on both the right and left sides or not fused, and then, the fusion rate was calculated. 
TAB LE 3 Micro-CT based histomorphometry of spines at 8 weeks

\begin{tabular}{|c|c|c|c|c|c|c|c|}
\hline Treatment group & & $\mathrm{TV}\left(\mathrm{mm}^{3}\right)$ & $\mathrm{BV}\left(\mathrm{mm}^{3}\right)$ & BV/TV (\%) & Tb.Th (mm) & Tb.N (1/mm) & Tb.Sp (1/mm) \\
\hline Group I & Carrier alone & $123.71 \pm 6.88$ & $47.44 \pm 8.56$ & $38.56 \pm 7.78$ & $0.22 \pm 0.05$ & $1.70 \pm 0.04$ & $0.41 \pm 0.11$ \\
\hline Group II & $3 \mu \mathrm{g}$ rhBMP-2 & $119.87 \pm 13.30$ & $44.19 \pm 9.45$ & $37.05 \pm 7.77$ & $0.21 \pm 0.06$ & $1.81 \pm 0.14$ & $0.46 \pm 0.13$ \\
\hline Group IV & $\begin{array}{l}3 \mu \mathrm{g} \text { rhBMP-2 + PTH (6 } \\
\text { times/week, total } \\
180 \mu \mathrm{g} / \mathrm{kg})\end{array}$ & $108.13 \pm 12.84$ & $\begin{array}{l}58.82 \pm 9.68^{*} \\
\text { (vs Group I, } \\
\text { II and III) }\end{array}$ & $\begin{array}{l}54.20 \pm 2.49^{*} \\
\text { (vs Group I, } \\
\text { II and III) }\end{array}$ & $\begin{array}{l}0.30 \pm 0.03^{*} \\
\text { (vs Group I, } \\
\text { II and III) }\end{array}$ & $1.84 \pm 0.29$ & $\begin{array}{l}0.20 \pm 0.05^{*} \\
\text { (vs Group I, } \\
\text { II and III) }\end{array}$ \\
\hline
\end{tabular}

Note: BV in the Group IV was larger than that in Group I, II, III with significant differences. BV/TV in the Group IV had higher values than the Group I, II, III with significant differences. Tb.N in the Group III had higher values than that in the Group I, II, IV with significant differences. Tb.Th in the Group IV had higher values than that in the Group I, II, III with significant differences. Tb.Sp in the Group IV had lower values than that in the Group I, II, III with significant differences. No significant difference was found between the other groups.

Abbreviations: BV, bone volume; BV/TV, bone volume fraction; Tb.N, trabecular number; Tb.Sp, trabecular spacing; Tb.Th, trabecular thickness; TV, tissue volume. ${ }^{*} p<.05$.
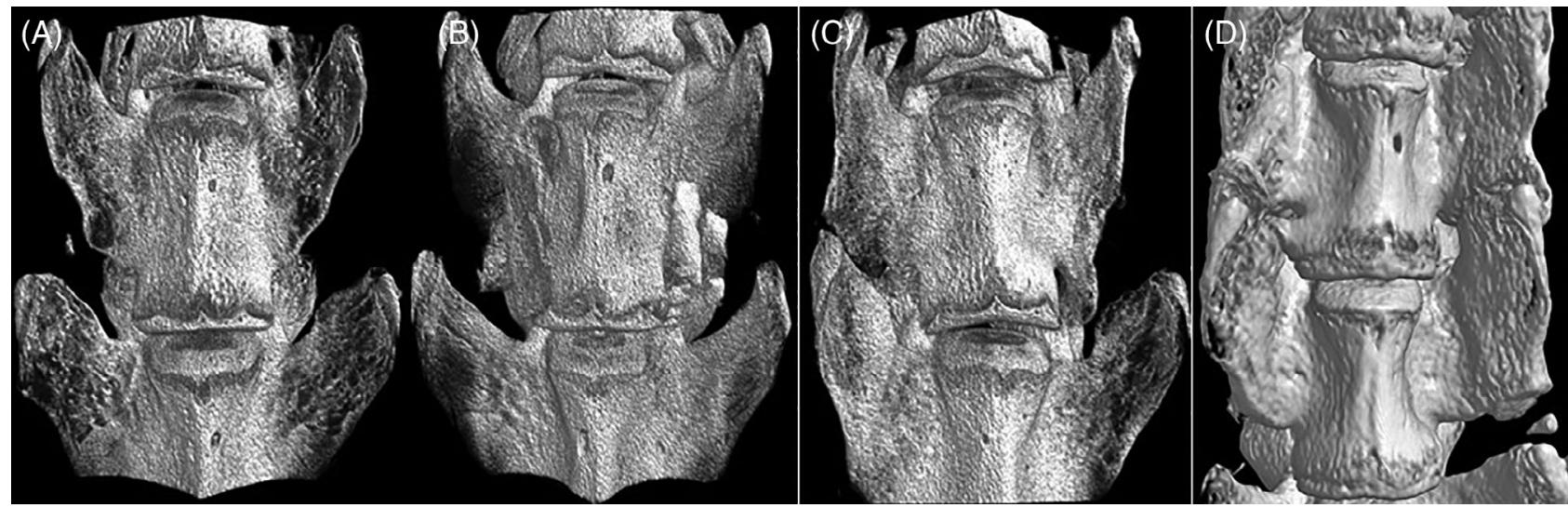

FIG URE 2 Representative three-dimensional micro-computed tomography anteroposterior images of rat spines obtained at 8 weeks post posterolateral umbar fusion surgery. A) Group I (carrier alone), (B) Group II (carrier containing $3 \mu \mathrm{g}$ rhBMP-2), (C) Group III (carrier containing $3 \mu \mathrm{g}$ rhBMP-2 + PTH (3 times [60 $\mu \mathrm{g} / \mathrm{kg}] /$ week, total $180 \mu \mathrm{g} / \mathrm{kg})$ ), and (D) Group IV (carrier containing $3 \mu \mathrm{g} \mathrm{rhBMP}-2+\mathrm{PTH}(6$ times[30 $\mu \mathrm{g} / \mathrm{kg}] / \mathrm{week}$, total $180 \mu \mathrm{g} / \mathrm{kg})$ )

\section{6 | Radiographic analysis}

The explanted spines obtained at the 8-week time point were photographed using a Softex X-ray apparatus (Softex CSM-2; Softex, Tokyo, Japan) employing HS Fuji Softex film (Fuji Film, Tokyo, Japan) at $45 \mathrm{~cm}$ with $30 \mathrm{kV}$ and $15 \mathrm{~mA}$ for $20 \mathrm{~s}$. The fusion between the L4 and L5 transverse processes in each rat was recorded as a percentage of the total area between the L4 and L5 that was filled with new bone. ${ }^{25}$ Three blinded independent observers scored the bone formation in each rat using a 5 -point scale: $0=$ no bone formation; $1=$ bone filling in $<25 \%$ of the area; 2 = bone filling in $25-50 \%$ of the area; $3=$ bone filling in $50-75 \%$ of the area; and 4 = bone filling in 75 to $100 \%$ of the area. The spines were scored on both the right and left sides.

\section{7 | Micro-CT analysis}

The spines were scanned by micro-CT using SkyScan 1172 (Bruker microCT, Kontich, Belgium) with a voxel size of $20 \mathrm{~mm}$. The data were collected at $100 \mathrm{kV}$ and $100 \mathrm{~mA}$ and reconstructed using the cone-beam algorithm. Each spine was set on the object stage, and sample scanning was performed over a $180^{\circ}$ rotation with an exposure time of $105 \mathrm{~ms}$. A cylindrical volume of interest with a diameter of $20 \mathrm{~mm}$ and a height of $27 \mathrm{~mm}$, which displayed the micro-structure of the rat vertebra as comprising cortical and cancellous bone, was selected. Data analysis of the area from the top of the L4 transverse processes to the bottom of the L5 transverse processes, including the vertebrae, was performed using CT Analyzer software (Bruker microCT). The spines were analyzed on both the right and left sides. Tissue volume (TV), bone volume (BV), bone volume fraction (BV/TV, \%), trabecular thickness (Tb.Th), trabecular number (Tb.N), trabecular spacing (Tb.Sp), and were measured.

\subsection{Analysis of serum markers of bone metabolism}

Just prior to euthanization of the animals, blood samples were collected and stored at $-80^{\circ} \mathrm{C}$ until analysis. Serum markers of bone 


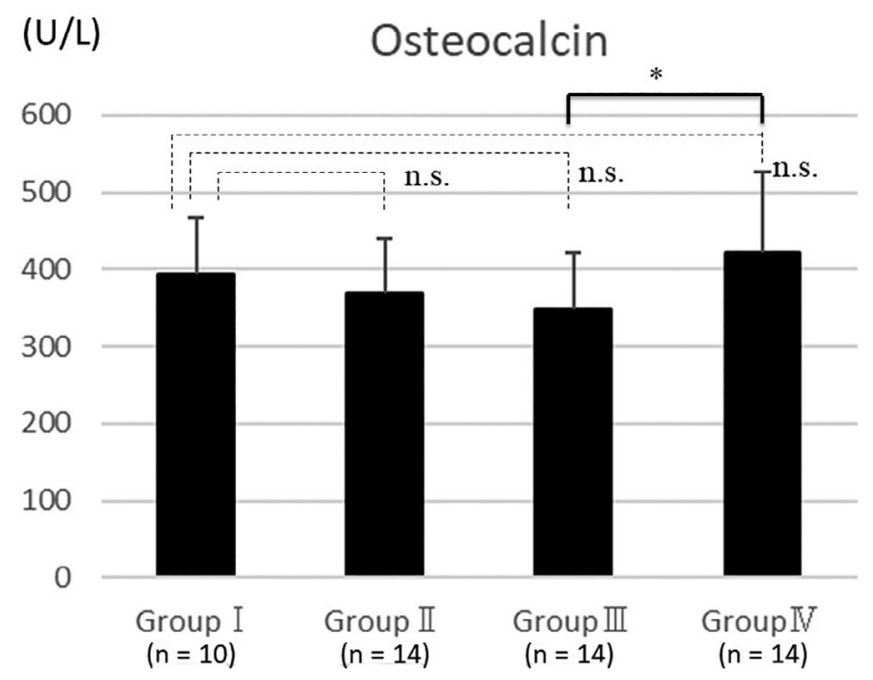

FIGURE 3 Enzyme-linked immunosorbent assay demonstrated that serum levels of osteocalcin showed no significant differences in Groups II, III, and IV compared with that in Group I. In contrast, a significant difference was observed between Groups III and IV $(p<.05)$. The bars represent the mean and the error bars represent the SD. The sample size of each group was Group I $(n=10)$, Group II $(n=14)$, Group III $(n=14)$, and Group IV $(n=14)$

metabolism were analyzed using an enzyme-linked immunosorbent assay specific for osteocalcin (Osteocalcin High Sensitive EIA Kit [rat]; Takara Bio, Shiga, Japan) and tartrate-resistant acid phosphatase-5b (TRACP5b) (RatTRAP Assay; Immunodiagnostic Systems Ltd., Boldon, UK) according to the manufacturer's instructions.

\section{9 | Histological analysis}

Eight weeks after implantation, the spines were dissected and the specimens were fixed in $40 \%$ ethanol, decalcified using standard $10 \%$ decalcifying solution $\mathrm{HCl}$ (Cal-Ex; Fischer Scientific, Fairlawn, New Jersey), washed with running tap water, and then transferred to $75 \%$ ethanol. Serial sagittal sections near the transverse processes were carefully cut at the level of the transverse process on both the right and left sides. The specimens were embedded in wax for sectioning. Sagittal sections $(5 \mathrm{~mm}$ ) were cut from the paraffin blocks using a microtome (LS-113; DAIWA-KOKI, Saitama, Japan). The sections were stained with hematoxylin and eosin for basic morphology. Three blinded independent observers scored histological bone formation. Histological fusion was defined as bony trabeculae bridging from one transverse process to the next. ${ }^{25}$ Fusion masses were assessed, and the extent of new bone formation was scored using the following scoring criteria: $1=$ fibrocartilage tissue filling $<25 \%$ of the gap area; 2 = fibrocartilage tissue filling 25 to $75 \%$ of the gap area; 3 = fibrocartilage and bone tissue filling 75 to $99 \%$ of the gap area; 4 = bridged with bone tissue, but the fusion masses comprise thin trabecular bone; and $5=$ completely bridged with abundant mature bone tissue. The spines were scored on both the right and left sides.

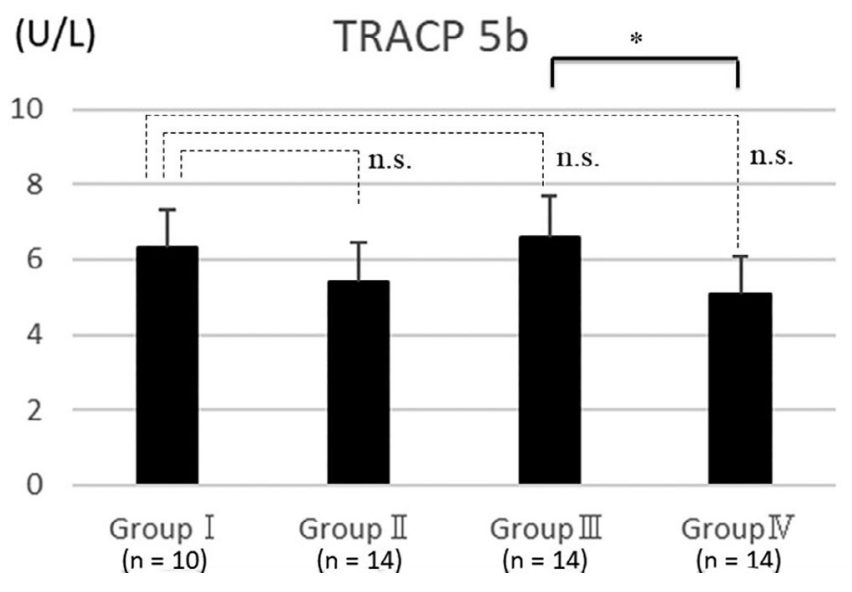

FIG URE 4 Serum levels of tartrate-resistant acid phosphatase-5b (TRACP5b) showed no significant differences between Groups II, III, and IV compared with that in Group I, whereas a significant difference was found between Groups III and IV $(p<.05)$. The bars represent the mean and the error bars represent the SD. The sample size of each group was Group I $(n=10)$, Group II $(n=14)$, Group III $(n=14)$, and Group IV $(n=14)$

\subsection{0 | Statistical methods}

All values are presented as mean (SD). The Statistical Package for the Social Sciences (SPSS) (V13; IBM Corporation, Armonk, NY) was used to perform ANOVA statistical analysis and the Tukey HSD (honesty significant differences) test as post-hoc analysis. $p$ values $<.05$ were considered significant. The kappa statistic was calculated as a measure of the interobserver reliability of the three independent blinded observers. The kappa statistic corrects the observed agreement for possible chance agreement among observers. Agreement was rated as follows: poor, $\kappa=0-0.20$; fair, $\kappa=0.21-0.40$; moderate, $\kappa=0.41$ 0.60 ; substantial, $\kappa=0.61-0.80$; and excellent, $\kappa>0.81$. A value of 1 indicated absolute agreement, whereas a value of 0 indicated agreement no better than chance.

\section{$3 \mid$ RESULTS}

No abnormal behavior or neurological deficits were noted in any of the 52 rats before or after the surgical procedure or at the time of euthanasia. No infection was found at the surgical site in any of the rats. There was no significant difference in weight gain between the four groups at 8 weeks.

\section{1 | Manual palpation}

Table 1 shows the proportion of subjects in each group who achieved fusion according to the three independent evaluators. Consistent agreement $(\kappa=0.864)$ was noted among the three independent observers who performed manual palpation. 
Eight segments in Group III ( $n=14$, segments $=28$ ) were assessed as fused (fusion rate, 28.6\%) and 10 segments in Group IV $(n=14$, segments $=28$ ) exhibited fusion (fusion rate, $35.7 \%$ ), whereas two segments in Group II ( $n=14$, segments $=28$ ) exhibited fusion (fusion rate, 7.1\%). None of the spines in Group I $(n=10$, segments $=20$ ) were fused (fusion rate, $0 \%)$. The subjects
(A)

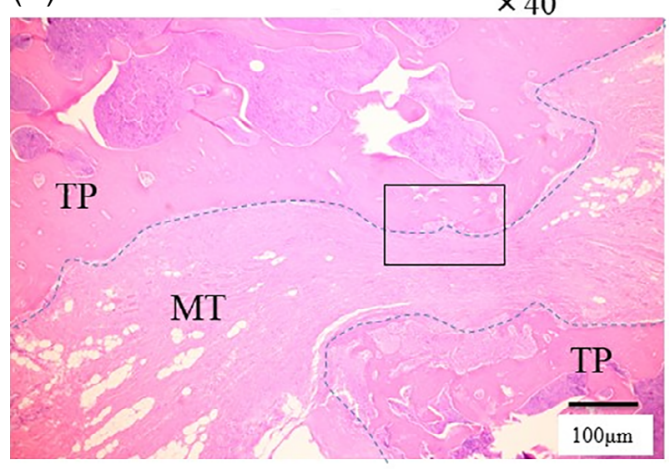

(C)

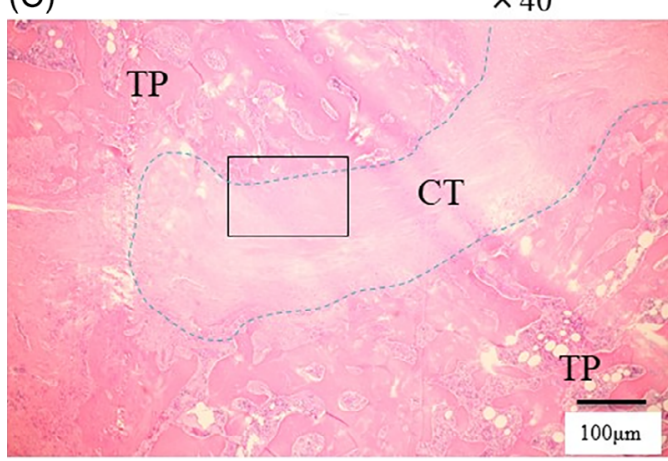

(E)

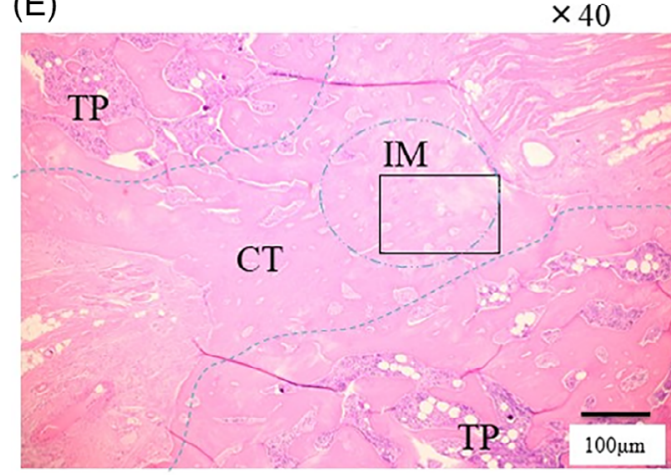

(G)

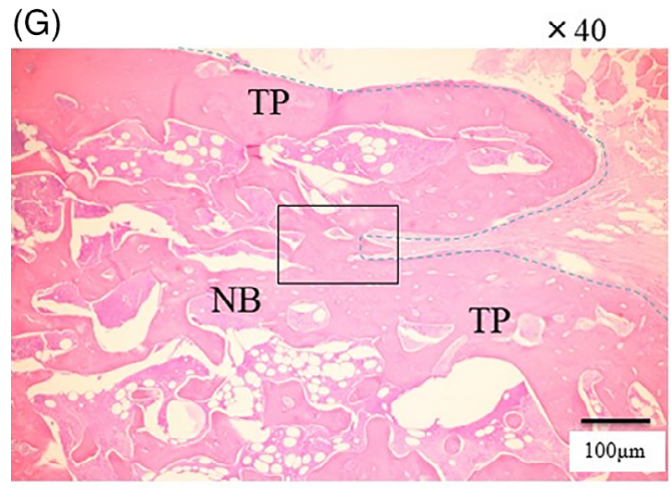

(B)

$\times 200$

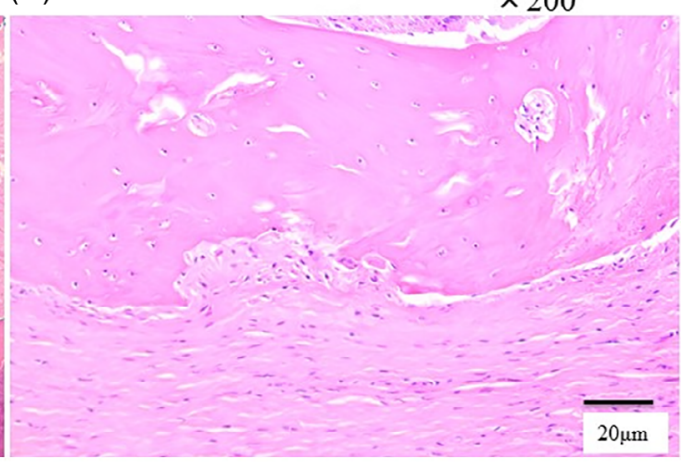

(D)

$\times 200$

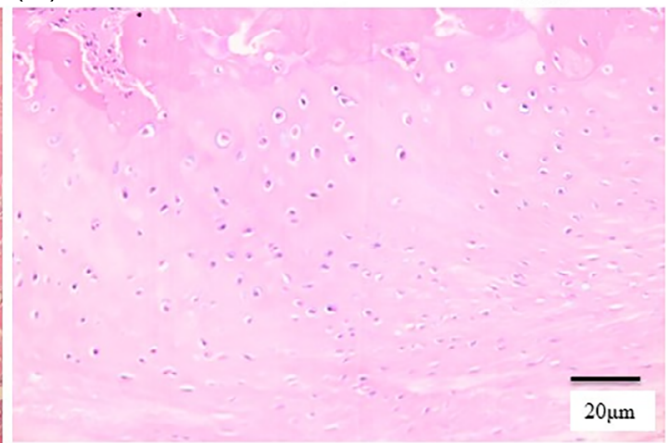

(F)

$\times 200$

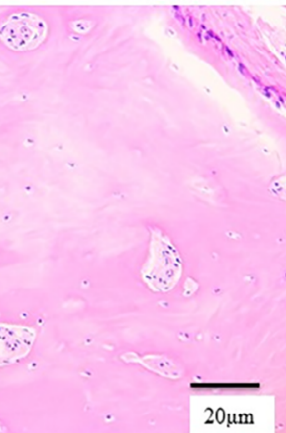

(H)

$\times 200$

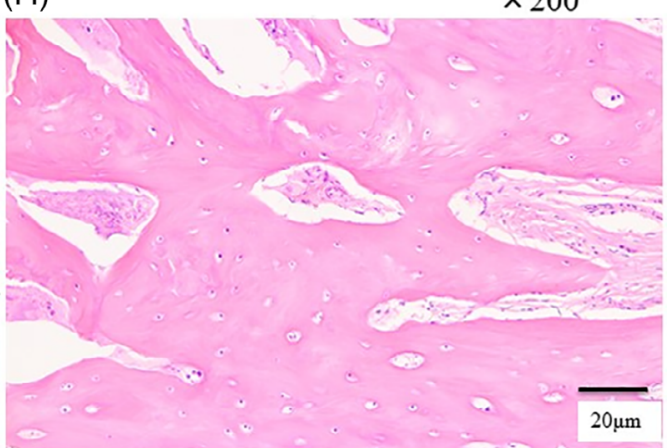


TAB LE 4 Histological fusion score at 8 weeks

\begin{tabular}{|c|c|c|}
\hline Treatment group & & $\begin{array}{l}\text { Score at } 8 \text { weeks } \\
\text { (mean } \pm S D)\end{array}$ \\
\hline Group I & Carrier alone & $0.10 \pm 1.02$ \\
\hline Group II & $3 \mu \mathrm{g} \mathrm{rhBMP}-2$ & $0.68 \pm 1.33$ \\
\hline Group III & $\begin{array}{c}3 \mu \mathrm{g} \text { rhBMP-2 }+ \text { PTH } \\
(3 \text { times } / \text { week, } \\
\text { total } 180 \mu \mathrm{g} / \mathrm{kg})\end{array}$ & $\begin{array}{l}2.66 \pm 1.21^{*} \text { (vs Group } \\
I \text { and II) }\end{array}$ \\
\hline Group IV & $\begin{array}{l}3 \mu \mathrm{g} \mathrm{rhBMP}-2+\text { PTH } \\
\text { (6 times } / \text { week, } \\
\text { total } 180 \mu \mathrm{g} / \mathrm{kg} \text { ) }\end{array}$ & $\begin{array}{l}3.15 \pm 1.73^{*} \text { (vs Group } \\
\quad \mathrm{I} \text { and II) }\end{array}$ \\
\hline
\end{tabular}

Note: The Group III and IV had higher histological fusion scores than the Group I and II significant differences. No significant difference was found between the other groups. ${ }^{*} p<.05$.

in Groups III and IV had a higher fusion rates than those in Groups I and II. There was no significant difference between the manual assessment scores of Groups III and IV, whereas significantly higher fusion rates were observed in Groups III and IV than in Group I $(p<.05)$.

\section{2 | Radiographic analysis}

Radiographs of the spines were obtained at 8 weeks. Consistent agreement $(\kappa=0.812)$ was noted among the three independent observers who graded the radiographs. The spines were scored on both the right and left sides. The average evaluation scores for each group are shown in Table 2, and the representative anteroposterior radiographs in each group at 8 weeks are shown in Figure 1. At 8 weeks postoperatively, Group III and IV showed evidence of bone formation between the L4 and L5 transverse processes, and bony bridging was detected. Mineralized callus bridging between the L4 and L5 transverse processes was detected in Group II, although the amount of callus was deemed insufficient. Group I showed no evidence of bone formation. The Group III and IV had higher radiographic scores than the Group I and II with significant differences $(p<.05)$. No significant difference was found between the other groups.

\section{3 | Micro-CT analysis}

A computer analysis of the micro-CT images revealed the volume of new bone and the quality of the spinal fusion area. The average micro-CT data based on the histomorphometry of each group are shown in Table 3, and the representative three-dimensional anteroposterior images in each group at 8 weeks are shown in Figure 2. Analysis revealed a statistical difference in the variance in the bone volume percentage. BV in the Group IV was larger than that in Group I, II, III with significant differences. BV/TV in the Group IV had higher values than the Group I, II, III with significant differences. Tb.N in the Group III had higher values than that in the Group I, II, IV with significant differences. Tb.Th in the Group IV had higher values than that in the Group I, II, III with significant differences. Tb.Sp in the Group IV had lower values than that in the Group I, II, III with significant differences. No significant difference was found between the other groups.

\subsection{Serum markers of bone metabolism}

Enzyme-linked immunosorbent assay demonstrated that serum levels of osteocalcin did not differ significantly between Groups II, III, and IV compared with those in Group I. In contrast, a significant difference was found between Group III and Group IV ( $p<.05)$ (Figure 3). Similarly, serum levels of TRACP5b did not differ significantly between Groups II, III, and IV compared with those in Group I. However, a significant difference was found between Group III and Group IV $(p<.05$; Figure 4).

\section{5 | Histological analysis}

Histological analysis of Group I showed a paucity of new bone formation and no evidence of fusion (Figure 5A,B). These images clearly demonstrate the muscle between the transverse processes for both specimens. Occasional evidence of new bone formation was observed, originating either from the decorticated transverse process or normal remodeling. A representative case in Group II showed distribution of cartilaginous tissue; however, there was fibrosis tissue and muscle fiber between the transverse processes and no evidence of

FIGURE 5 Sagittal histologic cross-section of the L4-L5 transverse processes of rat spines obtained at 8 weeks after posterolateral lumbar fusion surgery. (A) Group I animals, euthanized at 8 weeks postoperatively; magnification $\times 40$. (B) Group I animals, euthanized at 8 weeks postoperatively; magnification $\times 200$. These images clearly demonstrate muscle tissue (MT) between the transverse processes for both specimens. Occasional evidence of new bone formation was observed, originating either from the decorticated transverse process(TP)or normal remodeling. (C) Group II animals, euthanized at 8 weeks postoperatively; magnification $\times 40$. (D) Group II animals were euthanized at 8 weeks postoperatively; magnification $\times 200$. Distribution of cartilaginous tissue (CT) is observed; however, there was fibrosis tissue and muscle fiber between the transverse processes and no evidence of bone fusion. (E) Group III animals, euthanized at 8 weeks postoperatively; magnification $\times 40$. (F) Group III animals were euthanized at 8 weeks postoperatively; magnification $\times 200$. Analysis of Group III showed distribution of cartilaginous tissue and immature bone formation (IM), but no woven bone between TP. (G) Group IV animals, euthanized at 8 weeks postoperatively; magnification $\times 40$. (H) Group IV animals, euthanized at 8 weeks postoperatively; magnification $\times 200$. Group IV showed new bone (NB) formation bridging the transverse processes, demonstrating mature osteoid tissue and contracting trabeculae 
bone fusion (Figure 5C,D). Representative cases in Group III showed distribution of cartilaginous tissue and immature bone formation, but no woven bone between the transverse processes (Figure 5E,F). A representative case in Group IV showed new bone formation bridging the transverse processes, demonstrating mature osteoid tissue and contracting trabeculae (Figure 5G,H). Histological fusion scores are shown in Table 4. The spines were scored on both the right and left sides. Groups III and IV had significantly higher histological scores than Group I and II ( $p<.05)$. Consistent agreement ( $\kappa=0.862)$ was noted among the three independent observers.

\section{4 | DISCUSSION}

In this study, we investigated the optimal intermittent interval administration of PTH using BMP in a rat spinal fusion model. Posterolateral lumbar fusion in rats is well established as an acceptable model for measuring bone growth, and assessing bone fusion. ${ }^{25-32}$ A previous study reported that the amount of rhBMP-2 required to achieve $100 \%$ bone fusion rate in a spinal fusion model is $10 \mu \mathrm{g}^{25-32} ; 3 \mu \mathrm{g}$ of rhBMP-2 was insufficient to achieve $100 \%$ bone fusion in this model. Therefore, $3 \mu \mathrm{g}$ of BMP was appropriate for testing PTH administration to enhance the fusion induced by BMP-2. Although PTH demonstrated fracture healing in rat models, ${ }^{19}$ the most optimal dose is still being searched. Previous study demonstrated that dose of $5 \mu \mathrm{g} / \mathrm{kg} /$ day did not appear to be effective in altering the mechanical properties in rat model. ${ }^{20}$ Morimoto et al. reported successful spinal fusion with weekly doses of $180 \mu \mathrm{g} / \mathrm{kg} /$ week PTH in a rat spinal fusion model. ${ }^{33}$ Therefore, we adopted $180 \mu \mathrm{g} / \mathrm{kg} /$ week (three times/ week and six times/week). Due to the difference in metabolism between humans and rats, it is assumed that the six times weekly administration Group is approximately two times weekly administration in human, and the three times weekly administration Group is approximately once weekly administration in human. ${ }^{34}$ MicroCT results showed that $\mathrm{Tb}$.Th in the Group IV had higher values than that in the Group I, II, III with significant differences and Tb.Sp in the Group IV had lower values than that in the Group I, II, III with significant differences. These results indicated PTH has the effect of making thicker and strengthening the trabecular bone structure in newly formed bone when administered six times a week.

Earlier studies investigating the long-term daily administration of PTH in ovariectomized rats ${ }^{35,36}$ did not report its effects on bone metabolism markers. However, in a prior study, daily administration of PTH at a dose of $30 \mu \mathrm{g} / \mathrm{kg}$ for 12 months led to a $40 \%$ increase in osteocalcin, a bone formation marker, relative to the control Group. ${ }^{37}$ In addition, long-term intermittent administration of PTH significantly accelerated the modeling and remodeling of new BMP-induced bone in a rat spinal fusion model. ${ }^{38}$ However, there are no paper which investigates the optimal administration method of PTH in a rat spinal fusion model.

In our study, six-times-weekly administration of PTH at $30 \mu \mathrm{g} / \mathrm{kg}$ $(180 \mu \mathrm{g} / \mathrm{kg} /$ week) elicited an increase in osteocalcin following six times weekly administration of PTH compared with three times weekly administration. We also observed decrease in serum TRAP5b following six times weekly administration of PTH compared with three-times-weekly administration. These results suggest six times weekly administration in rat (approximately two times weekly administration in human) of PTH may enhance bone formation with no accompanying increase in bone resorption, Therefore, based on microCT results, so six times weekly administration in rat (approximately two times weekly administration in human) may make thicker and strengthen the trabecular bone structure in bone remodeling process.

The histological analysis showed that groups III and IV developed trabecular bone and mature bone cells that were not found in Groups I and II. Group IV also showed a nearly normal bone marrow appearance compared to Group III. This might be evidence of enhanced trabecular bone structure caused by more frequent PTH administration.

The limitation of this study was that we could not investigate the bone fusion process. We only checked the sacrificed rats at 8 weeks after surgery. In our Micro-CT imaging, it was necessary to let the sample stand still for about $30 \mathrm{~min}$, so we had to sacrifice the rat and remove the spine before examination. In other word, it was difficult to continuously observe images of living spine. Some treatments conditions of PTH administration could have resulted in more rapid fusion, ${ }^{22,33,38}$ but would not be visible on 8 weeks in the present study. Still, we found different administration methods of PTH on same doses have different effects on bone metabolism markers. Our findings cannot be applied directly to humans because rats exhibit different biological responses to drugs. However, we believe the information of the present study provide further evidence for understanding the effects of these treatments.

\section{5 | CONCLUSION}

In summary, frequent administration of PTH may be better in making thicker and strengthening the trabecular bone structure in newly formed bone in rat spinal fusion model using insufficient BMP-2.

\section{ACKNOWLEDGMENT}

This study was supported by JSPS KAKENHI grant number JP 19 K09556.

\section{CONFLICT OF INTEREST}

The authors declare no conflicts of interest.

\section{AUTHOR CONTRIBUTIONS}

Masashi Miyazaki and Hiroshi Tsumura conceived and designed the study. Toshinobu Ishihara collected the data. Shozo Kanezaki and Yuhta Tsubouchi analyzed the data. Masashi Miyazaki and Tetsutaro Abe wrote the manuscript. All authors have reviewed and revised the manuscript for important intellectual content. All authors have approved the final version to be published. 


\section{ORCID}

Masashi Miyazaki (D) https://orcid.org/0000-0002-1661-6817

\section{REFERENCES}

1. Boden SD. Overview of the biology of lumbar spine fusion and principles for selecting a bone graft substitute. Spine (Phila Pa 1976). 2002; 27:S26-S31.

2. Bridwell KH, Sedgewick TA, O'Brien MF, Lenke LG, Baldus C. The role of fusion and instrumentation in the treatment of degenerative spondylolisthesis with spinal stenosis. J Spinal Disord. 1993;6:461-472.

3. McGuire RA, Amundson GM. The use of primary internal fixation in spondylolisthesis. Spine (Phila Pa 1976). 1993;18:1662-1672.

4. West JL, Bradford DS, Ogilvie JW. Results of spinal arthrodesis with pedicle screw-plate fixation. J Bone Joint Surg Am. 1991;73:1179-1184.

5. Zdeblick TA. A prospective, randomized study of lumbar fusion. Preliminary results. Spine (Phila Pa 1976). 1993;18:983-991.

6. Kanatani M, Sugimoto $\mathrm{T}$, Kaji $\mathrm{H}$, et al. Stimulatory effect of bone morphogenetic protein-2 on osteoclast-like cell formation and boneresorbing activity. J Bone Miner Res. 1995;10:1681-1690.

7. Okamoto M, Murai J, Yoshikawa H, Tsumaki N. Bone morphogenetic proteins in bone stimulate osteoclasts and osteoblasts during bone development. J Bone Miner Res. 2006;21:1022-1033.

8. Wozney JM, Rosen V, Celeste AJ, et al. Novel regulators of bone formation: molecular clones and activities. Science. 1988;242:15281534.

9. Boden SD, Kang J, Sandhu H, Heller JG. Use of recombinant human bone morphogenetic protein-2 to achieve posterolateral lumbar spine fusion in humans: a prospective, randomized clinical pilot trial: 2002 Volvo award in clinical studies. Spine (Phila Pa 1976). 2002;27:26622673.

10. Suh DY, Boden SD, Louis-Ugbo J, et al. Delivery of recombinant human bone morphogenetic protein-2 using a compression-resistant matrix in posterolateral spine fusion in the rabbit and in the nonhuman primate. Spine (Phila Pa 1976). 2002;27:353-360.

11. Kanayama M, Hashimoto T, Shigenobu K, Yamane S, Bauer TW, Togawa D. A prospective randomized study of posterolateral lumbar fusion using osteogenic protein-1 (OP-1) versus local autograft with ceramic bone substitute: emphasis of surgical exploration and histologic assessment. Spine (Phila Pa 1976). 2006;31:1067-1074.

12. Glassman SD, Carreon L, Djurasovic M, Campbell MJ, Puno RM, Johnson JR. Posterolateral lumbar spine fusion with INFUSE bone graft. Spine J. 2007; 7:44-49.

13. Dimar JR, Glassman SD, Burkus KJ, Carreon LY. Clinical outcomes and fusion success at 2 years of single-level instrumented posterolateral fusions with recombinant human bone morphogenetic protein$2 /$ compression resistant matrix versus iliac crest bone graft. Spine (Phila Pa 1976). 2006;31:2534-2539.

14. Louis-Ugbo J, Kim HS, Boden SD, et al. Retention of 1251-labeled recombinant human bone morphogenetic protein-2 by biphasic calcium phosphate or a composite sponge in a rabbit posterolateral spine arthrodesis model. J Orthop Res. 2000;2(20):1050-1059.

15. Hock JM, Gera I, Fonseca J, Raisz LG. Human parathyroid hormone(1-34) increases bone mass in ovariectomized and orchidectomized rats. Endocrinology. 1988;122:2899-2904.

16. Watson P, Lazowski D, Han V, Fraher L, Steer B, Hodsman A. Parathyroid hormone restores bone mass and enhances osteoblast insulin-like growth factor I gene expression in ovariectomized rats. Bone. 1995;16:357-365.

17. Neer RM, Arnaud CD, Zanchetta JR, et al. Effect of parathyroid hormone (1-34) on fractures and bone mineral density in postmenopausal women with osteoporosis. N Engl J Med. 2001;344:1434-1441.

18. Nakamura $T$, Sugimoto $T$, Nakano $T$, Kishimoto $H$, Ito $M$, Fukunaga M. Randomized teriparatide [human parathyroid hormone (PTH) 1-34] once-weekly efficacy research (TOWER) trial for examining the reduction in new vertebral fractures in subjects with primary osteoporosis and high fracture risk. J Clin Endocrinol Metab. 2012;97:3097-3106.

19. Andreassen TT, Ejersted $\mathrm{C}$, Oxlund $\mathrm{H}$. Intermittent parathyroid hormone (1-34) treatment increases callus formation and mechanical strength of healing rat fractures. J Bone Miner Res. 1999;14:960-968.

20. Alkhiary YM, Gerstenfeld LC, Krall E, Westmore M, Sato M, Mitlak BH. Enhancement of experimental fracture-healing by systemic administration of recombinant human parathyroid hormone (PTH 1-34). J Bone Joint Surg Am. 2005;87:731-741.

21. Lina IA, Puvanesarajah V, Liauw JA, et al. Quantitative study of parathyroid hormone (1-34) and bone morphogenetic protein-2 on spinal fusion outcomes in a rabbit model of lumbar dorsolateral Intertransverse process arthrodesis. Spine (Phila Pa 1976). 2014;39:347-355.

22. Kanezaki S, Miyazaki M, Ishihara T, Notani N, Abe T, Tsumura H. Enhancement of the effects of intermittent parathyroid hormone (1-34) by bone morphogenetic protein in a rat femoral open fracture model. J Orthop Surg Res. 2019;29:403.

23. Jones AL, Bucholz RW, Bosse MJ, et al. Recombinant human BMP-2 and allograft compared with autogenous bone graft for reconstruction of diaphyseal tibial fractures with cortical defects. A randomized, controlled trial. J Bone Joint Surg Am. 2006;88:1431-1441.

24. Garrison KR, Shemilt I, Donell S, et al. Bone morphogenetic protein (BMP) for fracture healing in adults. Cochrane Database Syst Rev. 2010;16:CD006950.

25. Kodera R, Miyazaki M, Yoshiiwa T, Kawano M, Kaku N, Tsumura H. Manipulation of anabolic and catabolic responses with bone morphogenetic protein and zoledronic acid in a rat spinal fusion model. Bone. 2014;58:26-32.

26. Hayashi T, Lord EL, Suzuki A, et al. A comparison of commercially available demineralized bone matrices with and without human mesenchymal stem cells in a rodent spinal fusion model. J Neurosurg Spine. 2016;25:133-137.

27. Kaito T, Johnson J, Ellerman J, et al. Synergistic effect of bone morphogenetic proteins 2 and 7 by ex vivo gene therapy in a rat spinal fusion model. J Bone Joint Surg Am. 2013;95:1612-1619.

28. Miyazaki M, Sugiyama $O$, Tow $B$, et al. The effects of lentiviral gene therapy with bone morphogenetic protein-2-producing bone marrow cells on spinal fusion in rats. J Spinal Disord Tech. 2008;21:372-379.

29. Miyazaki M, Zuk PA, Zou J, et al. Comparison of human mesenchymal stem cells derived from adipose tissue and bone marrow for ex vivo gene therapy in rat spinal fusion model. Spine (PhilaPa 1976). 2008;33:863-869.

30. Miyazaki M, Sugiyama O, Zou J, et al. Comparison of lentiviral and adenoviral gene therapy for spinal fusion in rats. Spine (PhilaPa 1976). 2008;33:1410-1417.

31. Ishihara T, Miyazaki M, Notani N, Kanezaki S, Kawano M, Tsumura H. Locally applied simvastatin promotes bone formation in a rat model of spinal fusion. J Orthop Res. 2017;35:1942-1948.

32. Miyazaki M, Morishita $\mathrm{Y}, \mathrm{He} \mathrm{W}$, et al. A porcine collagen-derived matrix as a carrier for recombinant human bone morphogenetic protein-2 enhances spinal fusion in rats. Spine J. 2009;9:22-30.

33. Morimoto $\mathrm{T}$, Kaito $\mathrm{T}$, Kashii $\mathrm{M}$, et al. Effect of intermittent Administration of Teriparatide (parathyroid hormone 1-34) on bone morphogenetic protein-induced bone formation in a rat model of spinal fusion. J Bone Joint Surg Am. 2014;96:e107.

34. Kawabata R, Isogai Y, Takakura A, et al. Three-times-weekly administration of teriparatide improves vertebral and peripheral bone density, microarchitecture, and mechanical properties without accelerating bone Resorption in Ovariectomized rats. Calcif Tissue Int. 2015;97:156-168.

35. Sato $\mathrm{M}$, Zeng GQ, Turner $\mathrm{CH}$. Biosynthetic human parathyroid hormone (1-34) effects on bone quality in aged ovariectomized rats. Endocrinology. 1997;138:4330-4337.

36. Sato M, Ma YL, Hock JM, et al. Skeletal efficacy with parathyroid hormone in rats was not entirely beneficial with long-term treatment. J Pharmacol Exp Ther. 2002;302:304-313. 
37. Fox J, Miller MA, Newman MK, et al. Daily treatment of aged ovariectomized rats with human parathyroid hormone (1-84) for 12 months reverses bone loss and enhances trabecular and cortical bone strength. Calcif Tissue Int. 2006;79:262-272.

38. Kaito T, Morimoto T, Yoshikawa H, et al. Modeling and remodeling effects of intermittent administration of teriparatide (parathyroid hormone 1-34) on bone morphogenetic protein-induced bone in a rat spinal fusion model. Bone Rep. 2016;16: 173-180.
How to cite this article: Abe, T., Miyazaki, M., Ishihara, T., Kanezaki, S., Tsubouchi, Y., \& Tsumura, H. (2021). Optimal intermittent administration interval of parathyroid hormone 1-34 for bone morphogenetic protein-induced bone formation in a rat spinal fusion model. JOR Spine, 4(3), e1168. https:// doi.org/10.1002/jsp2.1168 